\title{
PROFESSIONAL ATTITUDES: A NEGLECTED ASPECT IN MEDICAL EDUCATION
}

\section{Murad Ali Shah}

The medical profession is under increased scrutiny with regards to the undesirable attitudes and behaviors of some of its members. There is a growing level of mistrust amongst the public for the medical profession as one hears cases of negligence, misconduct and unethical practices leading to legal suits and even violence. As a result, there is an increasing public demand for the transparency, accountability and quality assurance among the health professionals ${ }^{1}$.

Health care in Pakistan is undisputedly identified as one of the country's most corrupt sectors, according to surveys conducted by Transparency International ${ }^{2}$. While the commercialization of medical profession is cited as a common reason for dilution of quality, doubts have been raised regarding the quality of training ${ }^{2}$. Are the graduate doctors well trained to perform their clinical responsibilities?

With the alarming rise of medical negligence and cases of unprofessionalism, there is a dire need for educational leaders to come forward with creative strategies to overcome the crises in medical education and initiate reforms at the earliest ${ }^{3}$.

The health sector in Pakistan requires a change right from induction of the medical students till practice at community level. The following listed are proposed suggestions for the improvement in professionalism and ethics among doctors of Pakistan's health care system.

1. We should move away from the narrow focus on excellence in examination results towards a more liberal and exhaustive selection process focusing on 'desirable attributes' for medicine in addition to examination results.

2. Professionalism, ethics, communication skills, teamwork and managerial skills should be part of the core curriculum.

3. There should be proper and effective system of accountability and transparency in the medical field ensuring ethical practices.

4. There should be more community-based training both at the undergraduate and postgraduate level, strengthening the bond between the doctors and community.

5. The regulating bodies should play their role effectively safeguarding the integrity of both the doctors and patients.

\section{REFERENCES:}

1. Vinod Kumar CS, Kalasuramath S, Kumar CS, Jayasimha VL, Shashikala P. The need of attitude and communication competencies in medical education in India. J Educ Res Med Teacher. 2015;3(1):1-4.

2. Transparency International Pakistan [Internet]. Available from: http://www.transparency.org.pk/

3. Martin J, Lloyd M, Singh S. Professional attitudes: can they be taught and assessed in medical education? Clin Med (Lond). 2002;2(3):217-23.

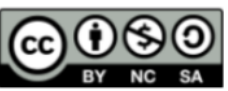

LICENSE: JGMDS publishes its articles under a Creative Commons Attribution Non-Commercial Share-Alike license (CC-BY-NC-SA 4.0). COPYRIGHTS: Authors retain the rights without any restrictions to freely download, print, share and disseminate the article for any lawful purpose. It includes scholarly networks such as Research Gate, Google Scholar, LinkedIn, Academia.edu, Twitter, and other academic or professional networking sites. 